\title{
Study on the Reference Function of Harry Potter Phenomenon on Culture Industry Development in China
}

\author{
Yuehong $\mathrm{Xu}^{1}$ and Xiao Liang ${ }^{2}$ \\ ${ }^{1}$ Management College of Minzu University of China, Beijing, China, 100081 \\ ${ }^{1}$ Management College of Minzu University of China, Beijing, China, 100081 \\ Email: zizi5054@sina.com s
}

Keywords: Harry Potter Phenomenon; Culture industry; Reference

\begin{abstract}
The culture industry has a huge burst of energy and vitality, and its development scale as well as degree has become an important sign evaluating the competitiveness of a nation or an industry. This paper firstly elaborates the theoretical basis of Harry Potter phenomenon based on the definition of culture industry as well as its basic elements; then, based on the description of Harry Potter phenomenon as well as the analysis of main industries (such as booking industry, film industry) in the industry chain and analysis on the derivatives, we are able to have references. This paper mainly starts from the perspectives of paying attention to cultural creation development and market-oriented operation mode, innovating cultural industry mechanism, building high-quality cultural team, improving the technology content of cultural industry, aiming to accelerate the development of Chinese cultural industry.
\end{abstract}

\section{Introduction}

In recent years, with the adjustment of economic structure as well as transformation of development patterns, the cultural industry rapid emerged. On $26^{\text {th }}$ September 2009, the State Department issued Cultural Industry Revitalization Plan, which is the first cultural industry plan since the establishment of China, marking the condition that cultural industry has become a leading and strategic one. In China, the Bohai culture industry circle, Yangtze River Delta culture industry circle, Pearl River Delta culture industry circle taking Beijing, Shanghai and Shenzhen as the center have been gradually formed, and the culture industry gradually becomes a means pushing the traditional industry reform as well as high-tech industry, satisfying the intellectual and cultural demands and improving culture prosperity. Besides, it also becomes an important force igniting the economic development mode transformation and accelerating the scientific development. On $25^{\text {th }}$ October 2011, the Sixth Plenary Session of the seventeenth Central Committee passed the proposal of CPC Central Committee decision On deepening the culture system reform and promoting cultural development as well as prosperity, trying the utmost to accelerate the development of cultural industry and make it become the economic pillar industry.

Yet, the cultural industry starts late with a glittering array of problems even though it has a good development momentum, which mainly show in the lack of product originality, imperfect market-oriented operation mode, system mechanism hindering the development of industry development and lack of talents. Therefore, we can clearly see that there are various contradictions and demerits in this field, if which cannot be properly solved, China shall enter into a bottleneck in terms of deepening the cultural industry development. This paper combines Harry Potter phenomenon to deeply analyze the mastering of basic elements of culture industry operation so as to obtain successful references and push the stable and healthy development of Chinese cultural industry. 


\section{Harry Potter phenomenon and Industrial Operation Analysis}

Harry Potter serialized novels tell the story of a little magician Harry Potter with seven parts and every part describes the experience of learning the magic. The story begins when Harry is 11 and he shall grow one year older until he is $17^{[1]}$. Even though the plot seems old-fashioned, it becomes a blockbuster throughout the world and is frequently awarded.

After the official publication of Harry Potter and the Sorcerer's Stone on $21^{\text {st }}$ July 1997 in England, it has been sold out for about 150,000 books in 15 months, which wins a list in the Guardian and the Times. What's more, it quickly wins various awards such as children book of the year etc. In 1998, American Scholars Press won the distribution right in America with the price of 105,000 dollars which then made Harry Potter become famous all over the world.$^{[2]}$

In 2001, Time Warner spent a large sum of money to take the first part of Harry Potter to the big screen, which won a big success. Until now, films of all of the seven parts have been finished and the box office skyrocketed. Furthermore, derivatives such as DVD, tools, computer games etc sold like hot cakes. In the context when the media is highly developed, Harry Potter has created a dazzling array of culture industry legends more than a book.

The Legends in Terms of Press and Communication Field. Ten years, seven novels, published in about 200 countries and regions with 375 million sales volume, translated in 70 languages with one million brand evaluation, all these numbers are able to declare that Harry Potter has powerful brand influence which are highly spoken of based on its language and cultural base. Besides, the author J. K. Rowling also ranks top 1 throughout the world in terms of writer social status.

Besides, in the course of series Harry Potter being published, relevant literature critics, companions, teaching guide, biographies as well as books related to research are also published. We find a dazzling array of books in the American library. For example, Critical Companion to J.K Rowling which is related to the author's life and work, Reading Harry Potter related to comments, The wisdom of Harry Potter, which conveys the Philosophy and ethics and Harry, a history related to the comments of readers. It is worth paying attention to is that many fans continue to write the book. There is even a dictionary called Harry Potter Dictionary, which is published to help readers to better understand Harry Potter. We can say that Harry potter seems like intangible electronic wave, which more or less invades the life of people.

Video and Art: Create a New Record in the History of Film. It happens that there is a similar case. Actors in eight series (the last series has two parts) become popular on the big screen. Supporting by Warner Brothers, eight series films won both box office and public praise and almost each one ranks top 50 in American film history. Until now, the total box office of Harry Potter series has exceeded 2.234 billion dollars which break the box office record 2.218 billion dollars created by Stars Wars. By the way, 23 series of 007 as well as 7 series of Batman also rank after Harry Potter. ${ }^{[3]}$

Moreover, Harry Potter series films have left a significant chapter in film history, which create various records. Among which, Harry Potter and the Deathly Hallows (next episode) creates a new record in terms of advance booking with 32 million dollars; in first three days, it won 169 million dollars box office which broke the record of 158 million dollars created by The Dark Knight; in terms of overseas market, it won 307 million dollars which also broke the record of 260 million dollars created by Pirates of the Caribbean 4. Influenced by Harry Potter, Transformers 3 also falls into shade and the Harry Potter and the Deathly Hallows (next episode) also becomes the top box office one. ${ }^{[4]}$

The Miracles of Derivatives Development and Popularity. The derivatives industry chains of Harry Potter also become important objects which are followed and studied. In North America and England, related derivatives such as DVD, television films, games, clothes, and stationeries all become best-seller goods. Relevant manufactures get more than $70 \%$ profits because of the popularity of Harry 
Potter books and films. At the same time, the development and hot selling of derivatives also play significant roles in promoting books and films.

The derivatives industries get the baton of Harry Potter books and films and also create magic as well as legends, which ignite the popularity of Harry Potter all over the world.

Unprecedented and Powerful Mass Foundation. Because of the exploding of books as well as films and the hot selling of derivatives, people spontaneously create social network accounts such as forum, Weibo etc for communication and the brand strikes root in the hearts of the people. At present, Harry Potter has won a large amount of fans even though there is not an official representative, people are still fond of Harry. Among the accounts, some fans make detailed magic list and analyze characters even the name only appears one time. As a result, there is a detailed pedigree.

People who find the attracting accounts with a glittering array of fans, yet are never exposed to Harry Potter before say that they are willing to read Harry Potter and gradually love the series novels. We can say that, the influence of such strong culture has infiltrated into al kinds of people/

To conclude, the mastering of basic industry operation elements makes Harry Potter becomes popular all over the world.

\section{The Basic Elements of Culture Industry Operation}

The basic elements of culture industry operation include economic, cultural resource condition, cultural environment, scientific level, culture management regime and culture product originality.

Economic Elements. The economic structure and industrial structure of a country, to a large extent determine the cultural industry structure. In developed countries, for example, between 1970s and 1980s, the economic globalization has accelerated the pace of developed countries transferring the labor-intensive industries to developing countries and the economic structure as well as industrial structure shall face adjustment while culture industry being highly valued. Around 1980s, developed countries consciously promote the cultural industry development and economic as well as industrial structure adjustment can be regarded as the basic background. Furthermore, economic development creates cultural consumers. The accelerated economic development brings along with different cultural industries and cultural products for people of different classes. On the one hand, economy stimulates the public cultural consumption, making sky rocketing public participate in cultural consumption; on the other hand, economy strengthens the leading role of public in terms of cultural product manufacturing which makes the cultural industry structure become the result the public choose freely. Besides, economic development also brings along with opportunities for cultural industries which need a large sum of investment, such as film industry, online games and theme parks.

Cultural Resource Condition. Firstly, cultural resource condition to a large extent effects the correlation among different sectors of the cultural industry in a region. For example, tourism and relevant industries with cultural heritage and natural heritage are developed; besides, industries with creation as well as talents which are related to copy right are prosperous. Secondly, cultural resource condition affects the content feature of cultural product. The cultural tradition and aesthetic habits are important parts of the cultural resource of a country, which shall bring along with national identity showing cultural art and demonstration means. For example, Chinese martial arts and martial arts movies, United States science fiction film, India film fantasy novels, magic novels in Latin America all show the deep imprint of a country's cultural tradition.

Cultural Environment. Cultural environment does not only provide opportunities and places for cultural activities as well as cultural diversity but also provide information in terms of cultural market condition and the consumption need and ability of culture. Cultural market condition is important content of cultural environment. Market is the basis for the survival and development of industry, and so is cultural industry. To establish and improve cultural market system, we have to create a cultural 
environment for fair competition among enterprises, which can be regarded as a basic work of cultural industry development and is of vital importance for cultural industry development. Based on this, accurately grasping the cultural market orientation with effective means to stimulate the consumption demands is beneficial to create a good environment for sustainable development.

Scientific Level. The scientific level has profound and critical effect on the cultural industry development. Culture, as products being manufactured and consumed has existed for a long time. Yet, the large-scale industrial manufacturing of cultural products, and the reform of cultural industry should rely on the technology innovation and technological advancement.

Cultural Management Regime. How can cultural management regime as well as cultural policies be adapted to the cultural development needs is an important factor for the healthy development of cultural industry development. According to international experience, in different stages of industrial development, the role Government played is often different. In different times, the controlling effect of government directly determines the cultural development trend. Therefore, in different periods of cultural industry development the controlling strength directly affects the rise and fall of industry development.

Cultural Product Originality. The essence of the culture industry is creative economy, and its core competence is human creativity. Modern cultural product is not a simple copy of traditional culture but advancement of traditional cultural resource depending on the intelligence and imagination of human as well as high technology, which can create great value. In the era when content is the most important factor, the basis of capital operation is good product because it is created by rich creativity of people. Besides, the difference and characteristics stimulated by originality can be beckoned as the basis and life of cultural industry. Therefore, cultural products are bases for the cultural product originality.

To sum up, economy, cultural resources, cultural environment, scientific level, cultural management regime and cultural product originality are all essential elements for the development of the cultural industry, and correctly grasping these elements is the basis for successfully develop cultural industry. The success of Harry Potter is an outstanding practitioner and beneficiary.

\section{The Reference Function of Harry Potter Phenomenon on Chinese Cultural Industry Development}

Pay Attention to the Cultural Creativity Development. The imaginary novel Harry Potter become hot in reality fully demonstrates that the cultural creation is the basis of the whole industry. Without good drama, we cannot make good films as well as derivatives people love deeply. Therefore, we can say that content as the most important factor is the source and foundation for cultural industry development.

In recent years, one of the reasons why Chinese cultural industry development being in a weak position is the lack of original creative force from content to forms. Take the domestic television programs created in 2010 as examples, Jade Palace Lock Heart became hot. Afterwards, similar dramas such as Hammer House Of Horror, Legend of love etc emerged. Concerning spy drama, there is also a glittering array of television programs. Therefore, there are repeated themes without innovation. In contrast, the cultural products exports of other countries do not copy other and there are various original products such as films, television dramas, music, media etc. Obviously, Chinese cultural products produced in such environment cannot win market share in international cultural market.

Therefore, while Chinese cultural products fully utilize rich cultural resources, the creation should not only pay attention to resource but also deeper cultural value so as to improve the cultural resource utilization ratio in order to create more economic value.

Pay Attention to the Market-oriented Industry Operation Mode. Harry Potter correctly grasps the market demand. Take Harry Potter novel as an example, from the market introduction phase, packaging, 
subsequent promotion to brand proliferation, the publishing house fully play the role of marketing so as to help Harry Potter accurately grasp the reader demand in each period to finally create a sales miracle in global book market.

Cultural products are not only propaganda materials, but also can satisfy the spiritual and cultural needs of people. Because of its own features, it can separate from daily necessities such as clothing, food, housing, transportation etc to add much to people's daily life. Therefore, correctly grasping market demand is of vital importance for industry development. In recent years, China put forward the slogan to vigorously develop the cultural industry, which was eagerly responded by municipalities to invest and develop cultural industry, yet finally failed because of the contradiction between market demand and manufacturing. The problem firstly shows in product selection because when introducing cultural products, most places do not carry out detailed market research before; besides, after introducing cultural products, they do not start from local need but copy from others trying to get profits; furthermore, the cultural products introduced are roughed made, and the quality is far behind the originals. Take American Disneyland and Universal Studios as examples, since 1990s, countless people started to build man-made theme park and $80 \%$ failed. The profitable project such as Beijing Happy Valley even has 300 million turnover in 2009, with 2 million 800 thousand visitors is inferior to Hong Kong Disney (5 million visitors), Tokyo Disneyland (17.7 million), Korea EVERLAND (9 million) and Lotte Paradise (7.5 million) . [5] The main reasons are: poor copies without clear themes and tourist have passive experience; the quality is poor with low entertainment value; repeated visiting, inconvenient transportation; poor maintenance, poor governance and insecurity and all these show that Chinese do not adequately take into account market demand.

It can be seen that while referring to the foreign ideas as well as successful experience we have to comply with the Chinese market operation mode and start from local market needs to highlight the market-oriented industry operation mode.

Innovative cultural industry regime. From Harry Potter's operation in America we can see that United States Government strongly supports this industry. Besides, via effective market competition mechanism, benefit incentives, risk control mechanism, Harry Potter carry out survival of the fittest so as to expand the scale merits which greatly improve the industry development. For example, after Warner winning the property right of Harry Potter as well as the certificate of Harry Potter's market operation right, it made various derivatives through property right separation. Through selling the franchise right with public bidding, various operators have equal rights. Of course, in terms of franchise, Warner conducted detailed planning as well as harsh standards in terms of market operation ability in order to prevent branch deterioration and brand value reduction. Obviously, without good market mechanism, Harry Potter series are only novels and films. We can conclude that good industry development relies on the regime construction.

For a long time, China confused non-profit cultural programs with operative culture industry which are all run by the government. The operative culture industry which should be led by the market relies on the government for a long time which confines the development of cultural programs and cultural industry; yet the non-profit cultural programs led by the government is in short of money and the public cultural service is also in shortage which make unbalanced consumption among town and countries as well as different groups which cannot satisfy the diversified demands of the public. Besides, there is not a clear line between the government and enterprises, and some local government adopts planned economy to manage the cultural industry in the market economy environment and therefore some administrative departments get trapped in concrete affairs which weaken the function of administrative management and macro-control. Besides, in terms of business management, the government controls the manufacturing management subject setting, manufacturing and selling in the whole journey, including radio, television, film and publishing. Therefore, enterprises have to get the certificate in each sector, including access permission, production license, and transmission license etc. As a result, the 
barriers of entering into the industry make many operation units shrink back.

Therefore, effective solve the market regime problem will greatly improve the cultural industry development. The following shows major countermeasures:

Firstly, property right reform: to carry out property right reformation we have to make c clear line between enterprises and government and the effective way is to establish modern enterprise system while the reform goal is to clear the affiliation relation. That is to say people who invest, shall get the benefit and to clearly elaborate benefits and responsibilities. The new regime should make enterprises become independent entity in terms of law and economy to make their own managerial decision, assume sole responsibility for their own profits or losses, and carry out self-discipline and development. Besides, we have to create an open and orderly market system. Most of the products, labor and manufacturing price should be transparent so as to realize the condition that market determines the price to create equal opportunities for enterprises.

Secondly, cultural management institution reform: we have to intensify the reform and abolish the institution overlapping to establish simple, effective, honest and authoritative government management regime.

Thirdly, government management function transformation: the government function should change from implementing to managing; the management focus should change from governmental cultural institutions and facilities to the whole society; the management means should change from administrative and direct management to legal and indirect means; construct trade association and strengthen the management function of the association.

Build high Quality Cultural Team. Talents are also important factors for the successful Harry Potter phenomenon. The creation of J. K. Rowling, the business mind of the agent, the mastering of the integrity as well as high-tech derivatives are all valuable wealth of this industry. Therefore, we can say that talents are indispensable.

Culture industry is a typical example of people-oriented modern economic development mode and the core resource of this industry is rich cultural collection and creative individual spirit. It is no exaggeration to say that talents should be the lifeblood of cultural industry. Therefore, the shortage of talents shall make the industry fall into a bottleneck.

For a long time, China's cultural market is not mature. Besides, particular ideology of cultural talents and education and training mechanism contribute to the condition that management talents or creative talents are scare. Even though various colleges and universities begin to set talent cultivation plan and subject the contradiction between talent shortage and rapid industry development will shine out in short time. Take Beijing as an example, creative talents occupy less than one thousandth of total employees while in New York, London, Tokyo, the ratio is more than 10\%. China lacks top creative talents and talents in terms of exhibition, online games, animation, copyright etc are also scarce. According to statistics, the culture industry needs about 300 thousand creative talents yet at present, there are only 30 thousand employees.

The cultural industry has to focus on talents in order to develop. Firstly, we have to train and introduce talents and cultivate professional and international entrepreneurs with strong political sense and excellent management ability. Besides, we also have to cultivate a professional technology team with high quality and innovative ability, especially talents who are familiar with WTO rules and market operation. Furthermore, we can optimize the talent team structure through recruitment, continuous education for archivists and training. Besides, we can establish talent incentive mechanism. Last but not the least, we have to push the distribution mechanism and the personnel system reform highlighting talents, strengthen the evaluation on talents, optimize talents resource allocation in order to create conditions for talents to give the full play.

Improve Technology Content of Cultural Industry. United States attaches great importance to high-tech application in the cultural industry, and takes scientific technology as an important driving 
force for cultural industry development. In 1990s, American book publishing company and audiovisual publishing company started to apply online technology into sales which makes it convenient for consumer selection and pushes the development of both of them. Harry Potter series movie and relevant theme park include high-tech elements and 3D effect makes people feel real. Besides, many scenes in the theme park reproduce the magic in the book. What's more, selling tools do not only include videos, $\mathrm{LD}, \mathrm{CD}$, toy, commemorate card, T-shirt and poster but also high-tech power so as to make an emerging industry. We can say that high technology is the strong back of Harry potter.

In contrast, the low level technology application makes China less competitive and creates an obstacle for development. At present, most of the Chinese exports are cultural products dominated by processing trade with traditional technology which can be replaced easily. Therefore, the development of modern technology and cultural circle will bring along with a new reform for cultural industry. On the one hand, we have to adopt high technology to arm, change and improve cultural products and drive the technology upgrading and structural reorganization so as to form cultural industry cluster with high tech content. Meanwhile, we have to apply new technology of other fields to improve the technology content of cultural products and extensively adopt modern science technology as well as management science to explore various cultural resources and improve traditional cultural industry so as to apply modern scientific results into every sector of art manufacturing, operation, management and service. On the other hand, we should establish a communication mechanism with science and culture. The cultural department should cooperate with scientific department to provide timely and effective technology for cultural industry. Finally, we have to positively promote the integration of cultural industry and technology industry especially information technology industry.

\section{References}

[1] http: //wenwen. sos0. corn / z / q42590436. html, 2011, 12, 17visit

[2] Jiang ShuQin, Research Review of Harry Potter, Inner Mongolia university journal (philosophy and social science edition ) $2008,40(1)$

[3] Harry Potter series box exceed 2.2 billion which become into the most of office hit film of the United States, http://www.022net.com/2011/7-25/434250352855128.html, 2012, 3, 12 visit

[4] Yi Fan, Ten years to sleep magic dream: hard to replicate "harry" miracle, http://ent.ifeng.com/movie/special/potter4/detail_2011_08/05/8209479_0.shtml 2012, 3, 14 visit

[5] Song XianKun, The Chinese theme park development consulting report. The Beijing China new record planning design research institute. China industry network publishing, 2009 